\title{
In-vitro Transit Tolerance of Probiotic Bacillus species in Human Gastrointestinal Tract
}

\author{
Ajitha S. Nair ${ }^{1}$, Aparna V. Dubhashi ${ }^{2}$ \\ Department of Microbiology, Guru Nanak Khalsa College, Matunga, Mumbai 400019
}

\begin{abstract}
The present work describes the tolerance of five potential probiotic Bacillus species towards acid and bile in human gastrointestinal tract by in-vitro studies. Artificial gastric and intestinal juice was prepared and adjusted to different pH values for acid and bile tolerance study. A time course analysis up to 4 hours was studied with respect to viability. There was a statistically significant growth response of isolates under high acidic conditions $(p<0.05)$ as confirmed by ANOVA test. Bacillus VS-5 was found to be the best with $98.78 \%$ survival rate for 3 hours exposure to $\mathrm{pH} 1.2$ and $98.10 \%$ to $2 \%$ bile concentration when exposed for 4 hours. Considering the residence time of food in stomach and intestine, this isolate proves to have an advantage of surviving and also proliferating in the intestinal tract, which is a desirable characteristic of probiotic cultures.
\end{abstract}

Keywords: Probiotic, Bacillus species, transit tolerance, gastric juice, ANOVA test

\section{Introduction}

Probiotics are live microorganisms which give health benefits to the host when administered in adequate amounts [1]. Industrial interest in foods, especially dairy products, containing probiotic strains has increased due to the knowledge of the benefits for bowel health and immunity. The food industry has been constantly looking out for new probiotic strains which would have a longer shelf life as well as more acid and bile tolerance. Probiotic bacteria are only transient in the intestinal tract and do not become permanent microflora of the host intestine. Hence they have to be regularly ingested in appropriate quantities to exhibit their positive effects [2].

Like Lactic acid bacteria, some species of the genus Bacillus, such as $B$. subtilis, $B$. licheniformis and $B$. coagulansare generally recognised as safe 'GRAS' bacteria in the food industry[3]. The genus Bacillus is a diverse group of Gram-positive, facultative anaerobic, endosporeforming bacteria and found extensively in nature. Due to the ability to produce endospores Bacillus survives extreme environmental conditions, including the ones it may encounter during food processing [4].

According to Guidelines approved by ICMR for evaluation of probiotics in food, in vitro tests to screen potential probiotic strains should essentially include resistance to gastric acidity and bile tolerance [5].

To be optimally functional, it is important that the probiotic strains should be viable during their transit to the gastrointestinal tract. After intake, these bacteria must therefore overcome two main biological barriers, the acidic environment of the stomach and bile secreted in the duodenum [6]. To make sure that they survive their passage through the gastrointestinal tract, prospective probiotic strains are screened for their tolerance to acid $\mathrm{pH}$ and bile. Different in vitro techniques have been used for this purpose [7-10]. In general, tolerance of non-indigenous organisms to gastrointestinal conditions is low. Hence methods including stress adaptation mechanisms of probiotic bacteria are being explored as possible approaches for studying their acid and bile resistance.

Bile which enters the duodenum of the small intestine reduces the survival of bacteria. This is because bacterial cell membranes, made up of lipids and fatty acids, are sensitive to destruction by bile salts [11].

The present study compares the transit tolerance of five Bacillus species under artificially prepared gastric and intestinal conditions in-vitro. Statistical significance of the growth response of isolates at different $\mathrm{pH}$ values was studied. A time course study to mimic gastric and intestinal residence time was also done to evaluate sustenance of isolates under such environments.

\section{Materials and Methods}

Five Bacillus species PL-2, VS-5, WBS-1, ATS and AVS, isolated from soil samples and having potential probiotic attributes like antibacterial activity against some gastrointestinal pathogens, synthesizing extracellular digestive enzymes and non-haemolytic nature were selected for the present study [12]

\section{Acid tolerance test:}

Artificial gastric juice was prepared to mimic stomach conditions. [13], adjusted to $\mathrm{pH} 1.2,2.0,3.0,4.0$ and 7.0 using $1 \mathrm{M} \mathrm{HCl}$ and sterilized. Pepsin solution which was filter sterilized was added at a final concentration of $4 \mathrm{mg} \%$ gastric juice. The tubes were inoculated with test Bacillus cultures $\left(10^{9} \mathrm{cells} / \mathrm{ml}\right)$, incubated at $37^{\circ} \mathrm{C}$ and viable counts carried out at hourly intervals for up to 3 hours of exposure.

\section{Bile tolerance test:}

Stock solution of 5\% sodium deoxycholate and 5\% sodium taurocholate was prepared and filter sterilized. Bile salt solutions of $0.5 \%, 1.0 \%, 1.5 \%$ and $2 \%$ concentration were prepared by mixing the two salts and using the diluent prepared as follows $5.0 \mathrm{~g}$ of $\mathrm{NaCl}, 0.6 \mathrm{~g}$ of $\mathrm{KCl}, 03 \mathrm{~g}$ of $\mathrm{CaCl}_{2}$ in 1 mole $/ \mathrm{L} \mathrm{NaHCO}$, adjusted to $\mathrm{pH} 8$ and autoclaved at $15 \mathrm{psi}$ for 15 minutes. 


\section{International Journal of Science and Research (IJSR) \\ ISSN (Online): 2319-7064}

Index Copernicus Value (2013): 6.14 | Impact Factor (2015): 6.391

Solutions were inoculated with test culture $\left(10^{9}\right.$ cells $\left./ \mathrm{ml}\right)$, incubated at $37^{\circ} \mathrm{C}$ and viable counts carried out at hourly intervals, for 4 hours [14].

The isolates were compared for their acid and bile tolerance using graphs, calculating their percentage survival and statistically using the SPSS (version 20) tool.

The percentage survival of the bacteria was calculated as follows [15]:

$\%$ Survival $=\quad \underline{\text { Log cfu of viable cells survived }} \times 100$ Log cfu of viable cells inoculated

Statistical analysis software tool SPSS (Statistical Package in Social Sciences) version 20.0 was applied to determine statistical significance of the study. ANOVA test was used to examine the differences in terms of viable counts among the five Bacillus cultures.A statistical significance was accepted at $\mathrm{p}<0.05$.

\section{Results and Discussion}

\section{Acid tolerance test}

The results of ANOVA revealed that there was a significant difference in the mean counts of the five Bacillus species at acidic $\mathrm{pH}$ of $1.2,2$ and 3. $(\mathrm{p}=0.000001,0.003$ and 0.028 respectively). However at $\mathrm{pH} 4$ and 7 there was no significant difference ( $\mathrm{p}=0.084$ and 0.06 respectively). Thus when exposed to high acidic environments, there is a significant statistical difference in the growth response of the five test cultures. In low acidic conditions however, the difference in growth response of cultures may not be statistically significant.

To survive passage through the stomach and small intestine, probiotic strains must tolerate the acidic and protease-rich conditions of the stomach. Acid tolerance is also important for the survival of probiotics in food. [16]
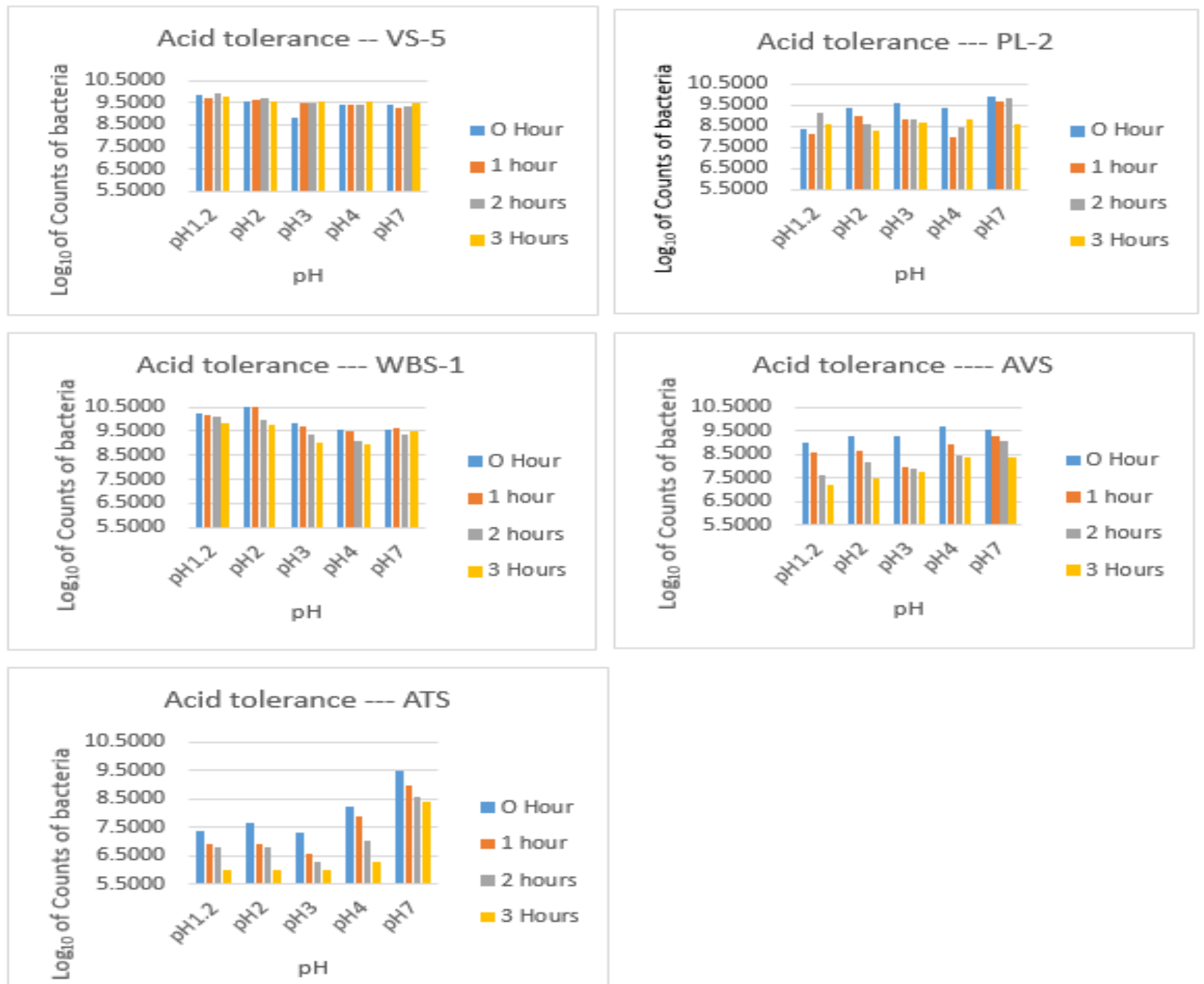

Figure 1: Acid tolerance of isolates at different $\mathrm{pH}$ values

Acid tolerance was studied for up to 3 hours of exposure as the mean transit time of food through the stomach is about 3 hours. [17] A characteristic decrease in viable count for initial one hour of acid exposure was observed in all cultures. This could be an initial lag phase during which the culture is adapting itself to the simulated gastric juice. After
2 hours of exposure the count increased and at the end of 3 hour exposure the count of cells again decreased, marginally. At pH 3 and 4, the number of cells increased at the end of 3 hours of exposure, showing that the cells could tolerate and proliferate in this acidity. 


\section{International Journal of Science and Research (IJSR) \\ ISSN (Online): 2319-7064}

Index Copernicus Value (2013): 6.14 | Impact Factor (2015): 6.391

Table 1: Percentage survival of test cultures to acidic $\mathrm{pH}$ exposure for 3 hours

\begin{tabular}{|c|c|c|c|c|}
\hline Culture code & \multicolumn{4}{|c|}{ \% Survival at acidic $\mathrm{pH}$} \\
\hline & 1.2 & 2.0 & 3.0 & 4.0 \\
\hline VS-5 & 98.78 & 99.41 & 100 & 100 \\
\hline PL-2 & 100 & 88.20 & 90.06 & 93.75 \\
\hline WBS-1 & 96.02 & 92.84 & 91.51 & 93.75 \\
\hline AVS & 80.27 & 80.68 & 83.11 & 86.08 \\
\hline ATS & 81.10 & 78.39 & 82.30 & 76.64 \\
\hline
\end{tabular}

The isolate VS-5, at a $\mathrm{pH}$ of 1.2 , showed 98 to $100 \%$ survival rates at all the $\mathrm{pH}$ values when exposed for 3 hours. It is therefore concluded that isolate VS-5 is the most acid tolerant among the 5 isolates, followed by WBS-1, PL-2, ATS, and AVS which tolerated acidic $\mathrm{pH}$ in the simulated gastric juice in the decreasing order.

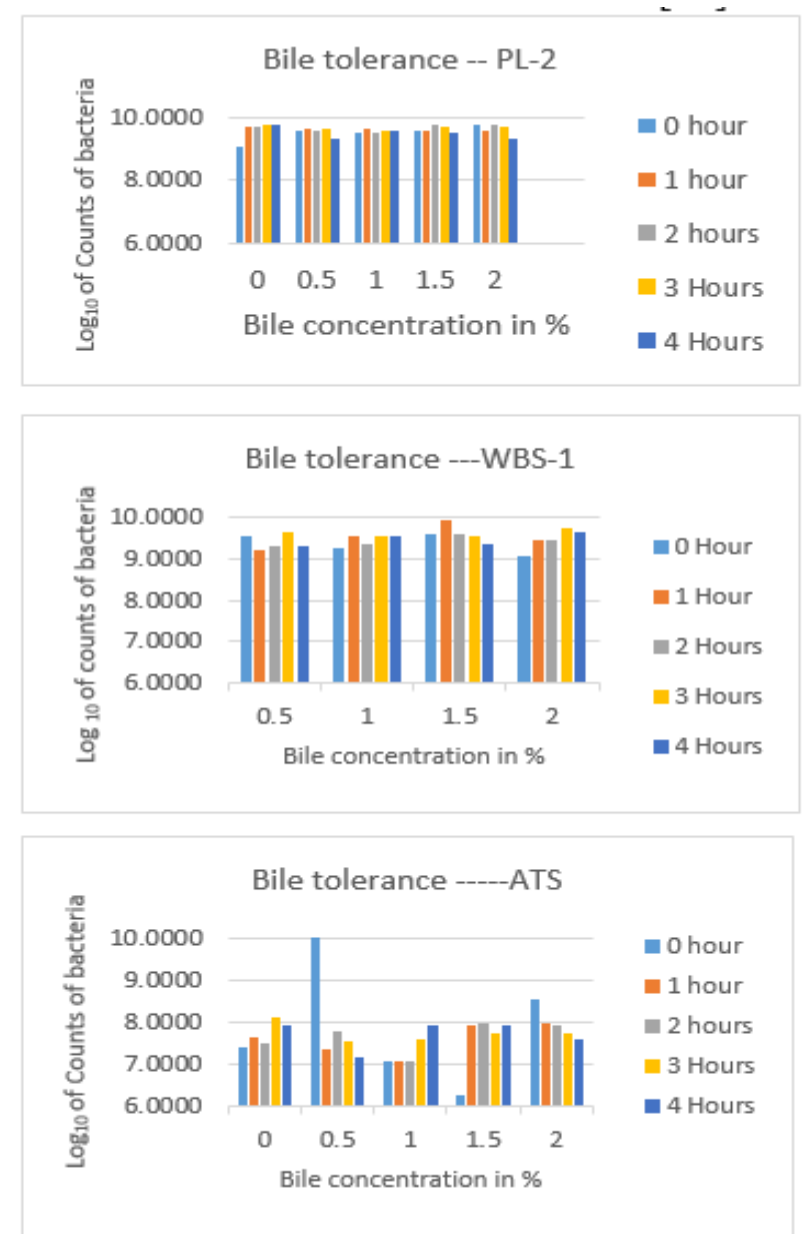

\section{Bile tolerance test}

Results of ANOVA suggest that there is no significant difference in the means of counts ofthe five Bacillus species at bile concentration of $0.5 \%$. $(\mathrm{p}=0.356)$. However at bile concentration of $1 \%, 1.5 \%$ and $2 \%$ there was a significant difference in the means of counts of test cultures. $(p=0.000$, 0.000001 and 0.000 respectively). Thus at higher bile salt concentrations the response in growth of test cultures was statistically significant.

Bile salt tolerance was studied for up to 4 hours as the mean transit time of food through the intestinal tract is found to be 4 hours[17].
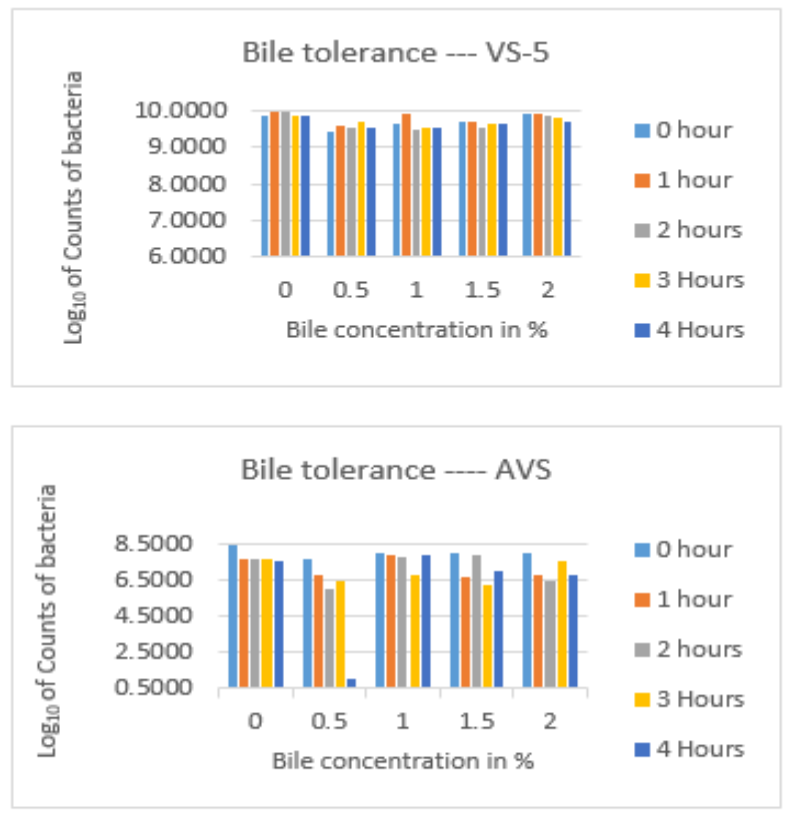

Figure 2: Bile tolerance of isolates at different concentrations

In-vitro tests to determine the inhibitory effect of bile salts on probiotic bacteria can be used to select the best strains on a relative basis

Table 2: Percentage survival of test cultures to bile salt exposure for 4 hours

\begin{tabular}{|c|c|c|c|c|}
\hline \multirow{2}{*}{$\begin{array}{c}\text { Culture } \\
\text { code }\end{array}$} & \multicolumn{4}{|c|}{$\begin{array}{c}\text { \% Survival at respective bile salt } \\
\text { concentration after 4 hours of exposure }\end{array}$} \\
\cline { 2 - 5 } & $0.5 \%$ & $1.0 \%$ & $1.5 \%$ & $2.0 \%$ \\
\hline VS-5 & 100 & 98.83 & 99.45 & 98.10 \\
\hline PL-2 & 97.43 & 100 & 99.30 & 95.73 \\
\hline WBS-1 & 97.34 & 100 & 97.24 & 100 \\
\hline AVS & 82.96 & 98.82 & 88.0 & 84.91 \\
\hline ATS & 70.37 & 100 & 100 & 88.93 \\
\hline
\end{tabular}

VS-5 showed $100 \%$ survival at $0.5 \%$ bile concentration up to 4 hours exposure. It also showed up to $99 \%$ survival even at $2 \%$ bile concentration confirming that it can survive intestinal conditions and proliferate there. Isolates PL-2 and WBS-1 showed minimum $92-95 \%$ and maximum up to $100 \%$ survival after exposure to the increasing concentrations of bile salts and tolerated even $2 \%$ bile salt concentration. ATS \& AVS showed inconsistent tolerance to bile salts. In comparison to results given by different strains of Lactobacillus acidophilus [18] which is commonly being used as a probiotic, these Bacillus species, especially VS-5, PL-2 and WBS-1 proved to be tolerating acid and bile better. The percent survival of these bacteria under acid and bile

\section{Volume 5 Issue 6, June 2016 www.ijsr.net}




\section{International Journal of Science and Research (IJSR) \\ ISSN (Online): 2319-7064 \\ Index Copernicus Value (2013): 6.14 | Impact Factor (2015): 6.391}

influence for 3 and 4 hours respectively is in the range of 80 to $90 \%$ while Lactobacillus acidophilus strains gave a percent survival of $50-80 \%$

\section{Conclusion}

Transit tolerance and survival of Bacillus probiotic cultures in acidic environment of stomach is $\mathrm{pH}$ dependent. When exposed to high acidic environments, there is a significant statistical difference the growth response. In low acidic conditions however, the difference in growth response of cultures may not be statistically significant.

Transit bile tolerance under simulated intestinal conditions is dependent on bile salt concentration. At higher bile salt concentrations the response in growth of test cultures was statistically significant. Among the five tested isolates, VS-5 proved to be tolerating the transit conditions best; suggesting that it could be considered as a novel probiotic candidate for human use.

\section{References}

[1] 'Evaluation of health and nutritional properties of probiotics in food including powder milk with live lactic acid bacteria: Report of a Joint FAO/ WHO Expert Consultation' [Online]2006. [25 Nov. 2008]. http://www.fao.org.

[2] Francesca Valerio et al 'In Vitro and In Vivo Survival and Transit Tolerance of Potentially Probiotic Strains Carried by Artichokes in the Gastrointestinal Tract' Appl Environ Microbiology. 2006 Apr; 72(4): 30423045.

[3] Sharpe et al (1989) 'Fermentation and downstream processing of Bacillus'. In Bacillus ed Harwood C.R. pp255-292

[4] Graumann PE. 2007. Bacillus: Cellular and Molecular Biology. Caister Academic Press, Hethersett, UK.

[5] N.K. Ganguly, ' S.K. Bhattacharya, ${ }^{2}$ et al 'ICMR-DBT Guidelines for Evaluation of Probiotics in Food' Indian J Med Res. 2011 Jul; 134(1): 22-25.

[6] Lankaputhra WEV, Shah NP. 'Survival of Lactobacillus acidophilus and Bifidobacterium spp. in the presence of acid and bile salts'. Cult Dairy Prod J 1995; 30:2-7.

[7] Tuomola E, Crittenden R, Playne M, Isolauri E, Salminen S. 'Quality assurance criteria for probiotic bacteria'. Am J ClinNutr 2001; 73: 393S-398S.

[8] Coeuret V, Gueguen M, Vernoux JP. 'In vitro screening of potential probiotic activities of selected lactobacilli isolated from unpasteurized milk products for incorporation into soft cheese'. J Dairy Res 2004; 71:451-60.

[9] Drago L, De Vecchi E, Nicola L, Colombo A, Gismondo MR. 'Microbiological evaluation of commercial probiotic products available in Italy'. $\mathbf{J}$ Chemotherapy 2004;16:463-7

[10] Noriega L, Gueimonde M, S'anchez B, Margolles A, de los ReyesGavil'an CG. 'Effect of the adaptation to high bile salts concentrations on glycosidic activity, survival at low $\mathrm{pH}$ and cross-resistance to bile salts in Bifidobacterium'.Int J Food Microbiology 2004; 94:79-86.
[11] L.Z. Jin, Y.W. Ho, N.Abdullah, and S. Jalaludin. 'Acid and bile tolerance of Lactobacillus isolated from chicken intestine'. Letters in Applied Microbiology 1998, 27, 183-185

[12] Ms PurviGujjar, Ms NidhiGoriwale, Mr AbhayTambe, Mrs Ajitha Nair and Dr AparnaDubhashi 'Screening of Industrially Important Bacillus Species and Their Cultivation on Agrowaste Substrates' IDEAS- ISSN 2320-0162 Vol 8, 2015-2016

[13] MałgorzataZiarno, DorotaZaręba 'Viability of Microflora of Market Fermented Milk Products In Simulated Conditions Of Gastric And Duodenum' Acta Sci. Pol., Technol. Aliment. 9(2) 2010, 227-236

[14] Hassan Hassanzadazar, Ali Ehsani, KarimMardani, JavadHesari. 'Investigation of antibacterial, acid and bile tolerance properties of lactobacilli isolated from Koozehcheese' Veterinary Research Forum. 2012; 3 (3) $181-185$

[15] Mehmet Tokatl J, Gök Gen Gülgör, SimelBaLderElmacJ, NurdanArslankoz E Gleyen, and FilizÖzçelik 'In Vitro Properties of Potential Probiotic Indigenous Lactic Acid Bacteria Originating from Traditional Pickles' BioMed Research International Volume 2015, Article ID 315819, 8 pages

[16] Lee YK, Salminen S. 'The coming of age of probiotics'. Trends Food SciTechnol 1995;6:241-5

[17] N W Read, M N Al-Janabi, A M Holgate, D C Barber, and C A Edwards 'Simultaneous measurement of gastric emptying, small bowel residence and colonic filling of a solid meal by the use of the gamma camera' Gut, 1986, 27, 300-308

[18] Gauri Dixit, Deepti Samarth, Vidya Tale, Rama Bhadekar* 'Comparative studies on potential probiotic characteristics of Lactobacillus acidophilus strains' EurAsian Journal of BioSciences Eurasia J Biosci 7, 1-9 (2013) 